\title{
Tolerability and Efficacy of Bevacizumab Monotherapy in Older Patients With Recurrent Ovarian Cancer
}

\author{
DAISUKE SHINTANI, HIROYUKI YOSHIDA, AKIRA YABUNO and KEIICHI FUJIWARA
}

Department of Gynecologic Oncology, Saitama Medical University International Medical Center, Saitama, Japan

\begin{abstract}
Background/Aim: The aim of this study was to compare the tolerability and efficacy of bevacizumab monotherapy between older and younger patients with recurrent ovarian cancer. Patients and Methods: We enrolled 32 patients with recurrent ovarian cancer who were treated with bevacizumab monotherapy and divided them into those who were 65 years and older $(n=12)$ and those younger than 65 years $(n=20)$. Results: Except for grade $\geq 3$ proteinuria, incidences of adverse events did not differ significantly between the groups. Although older patients exhibited more frequently cycle delay caused by non-hematological toxicities, this difference was not significant. There was no significant difference in tumor response and survival between the groups. Conclusion: Bevacizumab monotherapy was tolerable and effective for older patients with recurrent ovarian cancer compared with younger patients.
\end{abstract}

The age of patients with cancer is expected to increase worldwide in conjunction with an increase in life expectancy. It has been reported that, compared to younger populations, patients who are older than 65 years have approximately 10 times higher cancer incidence, which accounts for more than $50 \%$ of all solid cancer diagnoses (1). As would be expected, older cancer patients also have increased use of chemotherapeutic agents. However, the tolerability and efficacy of chemotherapy drugs remain unknown in older cancer patients. This is likely because there have been fewer reports in this patient population, and also clinical trials often exclude these patients. Although several previous clinical

This article is freely accessible online.

Correspondence to: Hiroyuki Yoshida, MD, Ph.D., Department of Gynecologic Oncology, Saitama Medical University International Medical Center, 1397-1 Yamane, Hidaka, Saitama, 350-1298, Japan. Tel: +81 429844637, Fax: +81 429844741, e-mail: hiro_y@saitamamed.ac.jp

Key Words: Older patients, chemotherapy toxicity, bevacizumab, ovarian cancer. trials included older cancer patients, they were not the primary targets of the trial, but instead, were usually part of subset analyses. Therefore, clinical practices often encounter difficulties in determining the efficacy, safety, and optimal chemotherapy regimens in older cancer patients.

The therapeutic problem for older cancer patients originates from the fact that treatment response is affected by age-related physiological changes that differ from those in younger patients. Some of the differences found in older patients include decreased drug absorption, liver metabolic capacity, and renal excretory function. In addition, older cancer patients usually have multiple chronic diseases, which can complicate cancer treatment both through the diseases and the possible deleterious interactions between anti-cancer and other medications.

Ovarian cancer is the leading cause of death from gynecological malignancies and the fifth most common cause of cancer-related deaths in women (2). The incidence of ovarian cancer increases with age; approximately $50 \%$ of patients with ovarian cancer are older than 65 years $(2,3)$. Ovarian cancer is most prevalent in the seventh and eighth decade of life, and it has been speculated that there will be a further increase in this age group in the future. While multiple studies have examined the tolerability and efficacy of chemotherapy in this population (4-7), optimal treatment strategies need to be further developed in older ovarian cancer patients.

Unfortunately, the majority of ovarian cancer patients are not diagnosed until an advanced stage of the disease simply because an effective screening method has not been developed and the characteristic symptoms of early stage disease have not been definitively described (8). The primary treatment method used in advanced ovarian cancer is chemotherapy, and the most commonly used agents are platinum and taxane. The humanized monoclonal antibody, bevacizumab, which targets vascular endothelial growth factor (9), has been applied as the first molecular targeted agent for use in newly diagnosed or recurrent ovarian cancer (10-13). Although this drug is now one of the key therapeutic agents used to treat ovarian cancer (14), the tolerability and efficacy in older ovarian cancer patients has 
yet to be definitively established (15-17). In addition, most of the studies that have examined the tolerability and efficacy of bevacizumab only investigated its use in combination with other cytotoxic agents (15-17). Therefore, information on the use of bevacizumab monotherapy in older cancer patients is currently lacking. Thus, this retrospective analysis was designed to examine the tolerability and efficacy of bevacizumab monotherapy in older ovarian cancer patients.

\section{Patients and Methods}

Patients. This retrospective study enrolled 32 patients with recurrent ovarian cancer who underwent treatment for the disease between August 2014 and March 2019. The Ethics Committee of Saitama Medical University International Medical Center approved this study, with all patients providing informed consent prior to undergoing the procedures. The International Federation of Gynecology and Obstetrics (FIGO) system was used to classify the stage of each patient (18). Patients were deemed eligible for the study if they had had histologically proven ovarian cancer that relapsed after at least one previous line of platinum-based chemotherapy, an Eastern Cooperative Oncology Group (ECOG) performance status (PS) $\leq 2$, in addition to having adequate baseline hematological, renal, and liver functions. Patients who underwent surgery within 28 days of bevacizumab therapy, had a history of gastrointestinal perforation or fistula, or had any evidence of bowel obstruction were excluded from this study.

Treatment. Every 21 days, enrolled patients were administered an intravenous dose of bevacizumab $(15 \mathrm{mg} / \mathrm{kg})$. During the first cycle, bevacizumab was administered for 1.5 hours, after which the infusion duration was shortened to $30-60 \mathrm{~min}$ if there were no significant adverse events observed. All treatments were continued unless there was progression of the disease or drug toxicity that required interruption of the treatment. If grade 3 toxicity or other adverse events occurred, treatments were delayed until there was resolution to grade 1 or less. All treatment delays were at the discretion of the investigators.

Toxicity and response evaluation. The National Cancer Institute Common Terminology Criteria for Adverse Events (ver. 4.0) was used to grade all adverse events during each cycle (19). Dose reductions were not allowed throughout treatment. The treatment responses were assessed every two or three cycles by computed tomography scans according to the Response Evaluation Criteria in Solid Tumors (RECIST) (20).

Statistical analysis. Patients in this age-specific retrospective analysis were separated into two groups, aged $<65$ and $\geq 65$ years. The age at the point where patients first began to receive bevacizumab therapy was defined as the patient's age. The chisquared test or Fisher's exact test were used to evaluate the categorical variables, as appropriate for category size. Progressionfree (PFS) and overall survival (OS) according to the age group were evaluated using Kaplan-Meier curves. Both PFS and OS were calculated from the date of initial bevacizumab treatment. Survival between the two groups was compared using a log-rank test. $p<0.05$ was used to determine significant differences.

\section{Results}

Patient characteristics. This retrospective study enrolled a total of 32 patients; $20(63 \%)$ were younger than 65 years and $12(37 \%)$ were 65 and older. Table I presents the comparison of the characteristics and tumor features between the two groups. The median age of the younger and the older group were 54.0 years (range $=41-62$ years) and 67.5 years (range $=65-74$ years), respectively. The PS score, primary tumor location, FIGO stage, and histology type exhibited no significant differences between the groups. The prevalence of hypertension, diabetes mellitus, cardiac disease, or pulmonary disease were also not significantly different between the groups. The two groups were additionally found to have an equivalent number of previous chemotherapy regimens. The platinum-sensitivity status (cancer that progressed $\geq 6$ months after platinum-based chemotherapy was considered to be platinum-sensitive, while cancer progressing $<6$ months was considered to be platinum-resistant) was not significantly different between the groups, with platinum-sensitivity found in approximately $15 \%$ of the subjects in both groups.

Feasibility. Table II shows the analysis of the feasibility of using bevacizumab monotherapy in the two groups. There was no significant difference in the numbers of cycles received between the two groups. Although both groups did not significantly differ in cycle delays, cycle delay caused by non-hematological toxicities were more frequent in older patients, but the difference was not significant ( $p=0.073$, Table II). There was also no difference between the younger and older groups in the frequency of treatment interruption. Progressive disease was the most common reason for treatment interruption in both groups.

Adverse events. As seen in Table III, incidences of hematological adverse events, such as anemia, neutropenia, and thrombocytopenia did not significantly differ between the groups. The older group exhibited a significantly higher incidence of grade $\geq 3$ proteinuria as compared to the younger group ( $p=0.032$, Table III). There was no significant difference in the incidence of nonhematological adverse events, such as hypertension, gastrointestinal perforation or fistula, and bleeding between the groups except for proteinuria. There were no treatment-related deaths observed in either group.

Response and survival. Table IV shows the best overall responses to bevacizumab monotherapy as measured by RECIST. Complete or partial responses were recorded in 2 $(10 \%)$ of the patients in the younger group, and in $2(17 \%)$ of the patients in the older group. The tumor response rate was not significantly different regarding bevacizumab monotherapy between the groups. There was also no difference in PFS between the younger (median PFS: 7.0 months) and older 
Table I. Patient baseline characteristics.

\begin{tabular}{|c|c|c|c|}
\hline & $\begin{array}{c}<65 \text { years } \\
(\mathrm{n}=20) \\
\mathrm{n}(\%)\end{array}$ & $\begin{array}{c}\geq 65 \text { years } \\
(\mathrm{n}=12) \\
\mathrm{n}(\%)\end{array}$ & $p$-Value \\
\hline Median age (range), years & $54.0(41-62)$ & $67.5(65-74)$ & \\
\hline ECOG PS & & & 0.20 \\
\hline 0 & $17(85)$ & $12(100)$ & \\
\hline 1 & $2(10)$ & $0(0)$ & \\
\hline 2 & $1(5)$ & $0(0)$ & \\
\hline Primary tumor location & & & $>0.99$ \\
\hline Ovary & $17(85)$ & $10(83)$ & \\
\hline Fallopian tube or peritoneum & $3(15)$ & $2(17)$ & \\
\hline Stage & & & 0.18 \\
\hline I & $3(15)$ & $0(0)$ & \\
\hline II & $2(10)$ & $3(25)$ & \\
\hline III & $11(55)$ & $4(33)$ & \\
\hline IV & $4(20)$ & $5(42)$ & \\
\hline Histology & & & 0.97 \\
\hline Serous & $10(50)$ & $7(58)$ & \\
\hline Endometrioid & $3(15)$ & $1(8)$ & \\
\hline Clear cell & $2(10)$ & $1(8)$ & \\
\hline Mucinous & $3(15)$ & $0(0)$ & \\
\hline Others & $2(10)$ & $3(25)$ & \\
\hline \multicolumn{4}{|l|}{ Comorbidity } \\
\hline Hypertension & $1(5)$ & $2(17)$ & 0.54 \\
\hline Diabetes mellitus & $0(0)$ & $1(8)$ & 0.38 \\
\hline Cardiac disease & $1(5)$ & $0(0)$ & $>0.99$ \\
\hline Pulmonary disease & $0(0)$ & $0(0)$ & $>0.99$ \\
\hline $\begin{array}{l}\text { Number of regimens } \\
\text { of previous chemotherapy }\end{array}$ & & & 0.32 \\
\hline 1 & $4(20)$ & $4(33)$ & \\
\hline 2 & $10(50)$ & $6(50)$ & \\
\hline$\geq 3$ & $6(30)$ & $2(17)$ & \\
\hline Platinum-sensitivity status & & & $>0.99$ \\
\hline Sensitive & $3(15)$ & $2(17)$ & \\
\hline Resistant & $17(85)$ & $10(83)$ & \\
\hline
\end{tabular}

ECOG PS: Eastern Cooperative Oncology Group performance status.

(median PFS: 6.5 months) group $(p=0.55)$ (Figure 1). In addition, as seen in Figure 2, there was no difference d in OS between the younger (median OS: 13.0 months) and older (median OS: 12.5 months) group ( $p=0.66$ ).

\section{Discussion}

This study evaluated tolerability and efficacy of bevacizumab monotherapy in older patients with recurrent ovarian cancer. The first important finding of this study was that older patients with recurrent ovarian cancer generally tolerated bevacizumab monotherapy as well as younger patients. Furthermore, our results also showed that older and younger patients exhibited toxicities with similar incidences. The other important finding of our current study was that there were no differences between older and younger patients
Table II. Number of cycles and feasibility of chemotherapy.

\begin{tabular}{lccc}
\hline & $\begin{array}{c}<65 \text { years } \\
(\mathrm{n}=20) \\
\mathrm{n}(\%)\end{array}$ & $\begin{array}{c}\geq 65 \text { years } \\
(\mathrm{n}=12) \\
\mathrm{n}(\%)\end{array}$ & $p$-Value \\
& & & 0.87 \\
\hline Number of cycles received & $5(25)$ & $3(25)$ & \\
$1-3$ & $3(15)$ & $2(17)$ & \\
$4-6$ & $12(60)$ & $7(58)$ & \\
$\geq 7$ & $4(20)$ & $5(42)$ & 0.20 \\
Cycle delay & & & \\
Reason for cycle delay & $2(10)$ & $0(0)$ & 0.52 \\
Hematological toxicity & $2(10)$ & $5(42)$ & 0.073 \\
Non-hematological toxicity & $20(100)$ & $11(92)$ & 0.20 \\
Treatment interruption & & & \\
Reason for treatment interruption & $2(10)$ & $3(25)$ & 0.34 \\
Toxicity & $18(90)$ & $8(67)$ & 0.17 \\
Progressive disease & $0(0)$ & $0(0)$ & $>0.99$ \\
Patient's withdrawal & & & \\
\hline
\end{tabular}

regarding the efficacy of bevacizumab monotherapy. In addition, there was no significant difference between the two groups with regard to tumor response rate, PFS or OS.

With the exception for grade $\geq 3$ proteinuria, our study demonstrated that bevacizumab monotherapy in older and younger patients with recurrent ovarian cancer did not differ with regard to the incidence of toxicities. Although older patients did exhibit more frequent non-hematological toxicities related to treatment delays, this difference was not significant. Older patients also appeared to well tolerate bevacizumab monotherapy. To date, the tolerability of bevacizumab therapy in older ovarian cancer patients has only been investigated in a limited number of studies. Selle et al. have evaluated bevacizumab-containing therapy tolerability when used as a first-line treatment in older patients with ovarian cancer (17). The findings of their study indicated that there were higher incidences of all grade anemia, diarrhea, and grade $\geq 3$ hypertension, and thromboembolic events in ovarian cancer patients aged $\geq 70$ years as compared to those $<70$ years. Conversely, both age groups had a similar incidence of grade $\geq 3$ proteinuria. Solio et al. have examined older patients with platinum-resistant recurrent ovarian cancer and evaluated the tolerability of the administration of bevacizumab-containing therapy (16). Their results indicated that patients aged 65 years or older exhibited a more frequent incidence of grade $\geq 3$ hypertension compared to those younger than 65 years. However, there was no prominent increase in the incidence of proteinuria, gastrointestinal perforation or other adverse events associated with bevacizumab. Another retrospective study that examined bevacizumab-containing therapy in ovarian cancer patients found that patients older than 70 years had a greater 
Table III. Worst degree of toxicities by age group (NCI-CTC 4.0).

\begin{tabular}{|c|c|c|c|c|c|c|}
\hline & \multicolumn{3}{|c|}{ All grades } & \multicolumn{3}{|c|}{ Grade $\geq 3$} \\
\hline & $\begin{array}{c}<65 \text { years } \\
(\mathrm{n}=20) \\
\mathrm{n}(\%)\end{array}$ & $\begin{array}{c}\geq 65 \text { years } \\
(\mathrm{n}=12) \\
\mathrm{n}(\%)\end{array}$ & $p$-Value & $\begin{array}{c}<65 \text { years } \\
(\mathrm{n}=20) \\
\mathrm{n}(\%)\end{array}$ & $\begin{array}{c}\geq 65 \text { years } \\
(\mathrm{n}=12) \\
\mathrm{n}(\%)\end{array}$ & $p$-Value \\
\hline \multicolumn{7}{|l|}{ Hematological } \\
\hline Anemia & $10(50)$ & $5(41)$ & 0.72 & $1(5)$ & $0(0)$ & $>0.99$ \\
\hline Neutropenia & $3(15)$ & $1(8)$ & $>0.99$ & $0(0)$ & $0(0)$ & $>0.99$ \\
\hline Thrombocytopenia & $4(20)$ & $1(8)$ & 0.63 & $1(5)$ & $0(0)$ & $>0.99$ \\
\hline \multicolumn{7}{|l|}{ Non-hematological } \\
\hline Nausea & $1(5)$ & $0(0)$ & $>0.99$ & $0(0)$ & $0(0)$ & $>0.99$ \\
\hline Vomiting & $0(0)$ & $0(0)$ & $>0.99$ & $0(0)$ & $0(0)$ & $>0.99$ \\
\hline Diarrhea & $0(0)$ & $0(0)$ & $>0.99$ & $0(0)$ & $0(0)$ & $>0.99$ \\
\hline Hypersensitivity & $1(5)$ & $0(0)$ & $>0.99$ & $0(0)$ & $0(0)$ & $>0.99$ \\
\hline Bleeding & $0(0)$ & $0(0)$ & $>0.99$ & $0(0)$ & $0(0)$ & $>0.99$ \\
\hline Thrombosis & $0(0)$ & $0(0)$ & $>0.99$ & $0(0)$ & $0(0)$ & $>0.99$ \\
\hline Fistula or perforation & $1(5)$ & $1(8)$ & $>0.99$ & $1(5)$ & $1(8)$ & $>0.99$ \\
\hline Hypertension & $2(10)$ & $4(33)$ & 0.17 & $0(0)$ & $1(8)$ & 0.38 \\
\hline Proteinuria & $5(25)$ & $6(50)$ & 0.15 & $2(10)$ & $6(50)$ & 0.032 \\
\hline
\end{tabular}

NCI-CTC 4.0: National Cancer Institute Common Terminology Criteria for Adverse Events version 4.0.

incidence of grade $\geq 3$ hypertension as compared to those aged 70 years or younger (15). As compared to our current study, the incidence of adverse events reported for bevacizumab therapy in these other reports are inconsistent with regard to our findings. Unlike our present work, these previous studies have reported that especially older patients had a more frequent incidence of grade $\geq 3$ hypertension as compared to younger patients. There could be several reasons responsible for these differences. For example, the ages examined could have contributed to different results, as the previous studies used older age cutoffs as compared to the present study. Since the risk of hypertension is associated with a higher age, the higher the age cutoff that is used the greater the chance of hypertension. Furthermore, the previous reports have also found a higher proportion of patients with hypertension in the older subgroup at baseline as compared to that in our current study. Thus, this could be the reason why the previous study had a higher incidence of grade $\geq 3$ hypertension as compared to our current study. Another study has also reported that the administration of bevacizumab in patients with hypertension at baseline was a risk factor for developing severe hypertension (15). One major difference between these studies was the administration of bevacizumab in combination with other cytotoxic agents. Bevacizumab has usually been combined with other cytotoxic agents, such as paclitaxel or carboplatin. In contrast, our current study administered bevacizumab as single-agent therapy.

There are only a few reports regarding the tolerability of bevacizumab monotherapy in patients with ovarian cancer. Burger et al. have reported a phase II trial evaluating the
Table IV. Best overall response to bevacizumab by age group.

\begin{tabular}{lccc}
\hline & $\begin{array}{c}<65 \text { years } \\
(\mathrm{n}=20) \\
\mathrm{n}(\%)\end{array}$ & $\begin{array}{c}\geq 65 \text { years } \\
(\mathrm{n}=12) \\
\mathrm{n}(\%)\end{array}$ & $p$-Value \\
\hline Response & & & 0.44 \\
$\quad$ Complete response & $0(0)$ & $0(0)$ & \\
Partial response & $2(10)$ & $2(17)$ & \\
Stable disease & $14(70)$ & $8(62)$ & \\
Stable disease $\geq 12$ months & $4(20)$ & $2(17)$ & \\
Progressive disease & $4(20)$ & $1(8)$ & \\
Not evaluable & $0(0)$ & $1(8)$ & \\
\hline
\end{tabular}

tolerability of bevacizumab monotherapy in relapsed ovarian cancer (21). They reported that the incidence rate of grade $\geq 3$ hypertension was $9.7 \%$, while grade $\geq 3$ proteinuria and gastrointestinal perforation were not observed. Another phase II study investigating bevacizumab monotherapy in relapsed ovarian cancer showed that the incidence rate of grade $\geq 3$ hypertension was $9.1 \%$, while that of gastrointestinal perforation was $11.4 \%$ (22). The incidence of grade $\geq 3$ hypertension in these previous reports has been higher than our study. Conversely, grade $\geq 3$ proteinuria was more frequent in our study. It is difficult to speculate on the reason for the difference in the incidence of adverse events between previous reports and our study because these previous studies did not compare older and younger patients, nor did they mention pre-existing hypertension. To the best of our knowledge, our study is the first to investigate the tolerability 


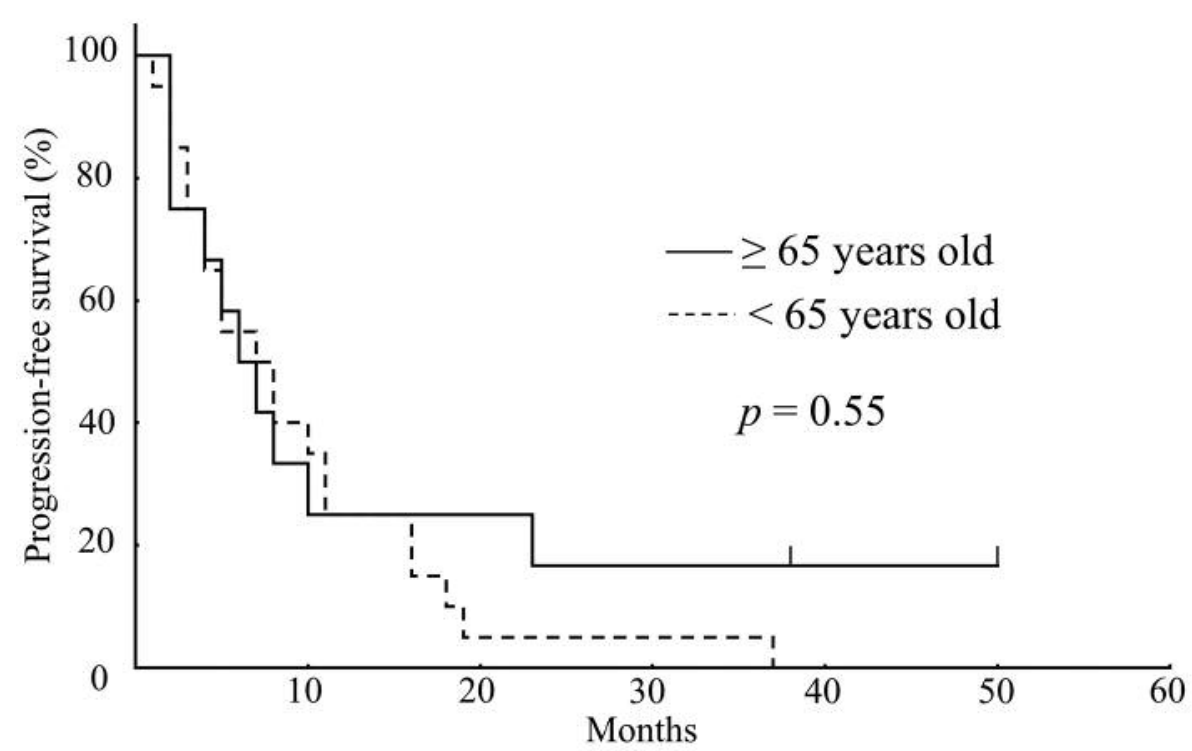

Figure 1. Kaplan-Meier survival analysis showed no significant difference in progression-free survival between older (solid line; $n=12$ ) and younger (dashed line; $n=20$ ) patients ( $p=0.55$; log rank test).

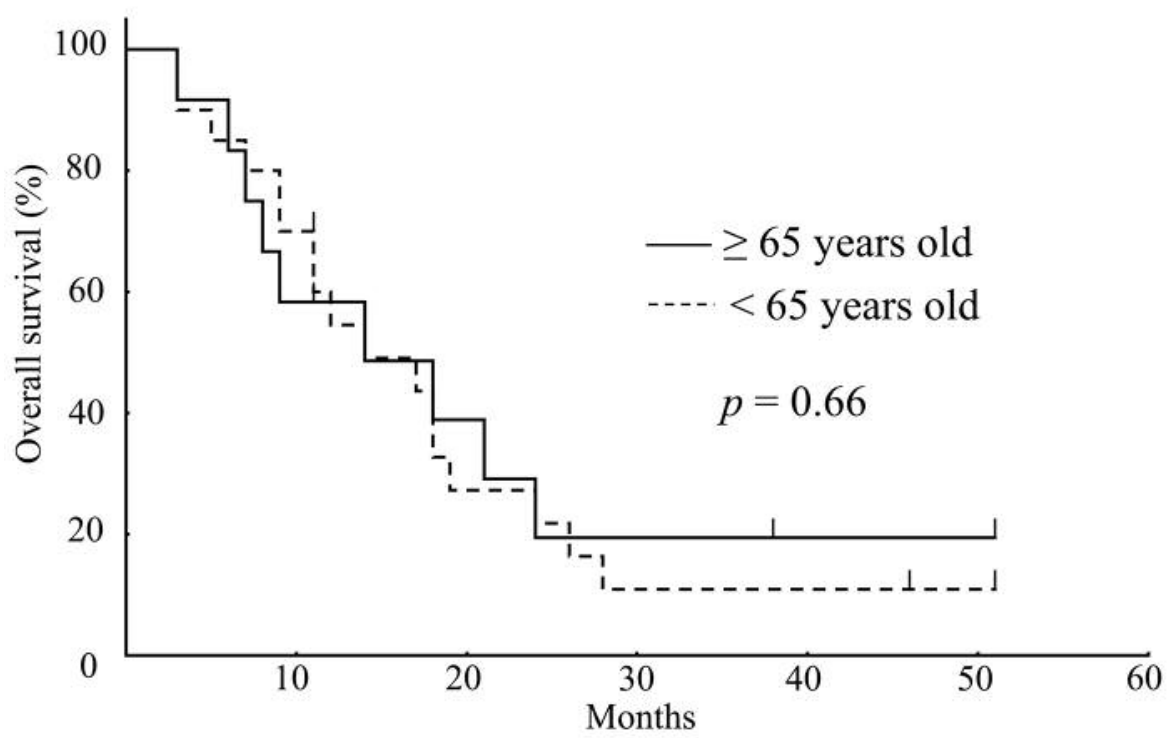

Figure 2. Kaplan-Meier survival analysis showed no significant difference in overall survival between older (solid line; $n=12$ ) and younger (dashed line; $n=20)$ patients ( $p=0.66$; log rank test).

of bevacizumab monotherapy in older ovarian cancer patients. Further research into the tolerability of bevacizumab monotherapy in the older population is necessary.

Our study also demonstrated that there was no difference in the efficacy of bevacizumab monotherapy between older and younger patients. The tumor response rates did not differ significantly between the two age groups. Additionally, the two age groups did not significantly differ in PFS or OS. Several previous reports have suggested that the efficacy of bevacizumab-containing therapy is similar in older and younger patients with ovarian cancer (15-17). Although these reports investigated treatment with bevacizumab in combination with other cytotoxic agents, the results are consistent with our study, which evaluated bevacizumab monotherapy. So far, only a few reports have investigated the efficacy of bevacizumab monotherapy in 
recurrent ovarian cancer (21-23), and the results of these reports are almost identical to our study. Bevacizumab therapy seems to have the same efficacy regardless of patients age, but additional studies are required to draw a final conclusion.

One of the limitations of our study is that it is a retrospective study that was carried out in a single cancer center. Thus, this decreases the generalizability of the results. Furthermore, there has been no definitive confirmation of the activity of bevacizumab monotherapy in recurrent ovarian cancer patients. Although several reports have shown that bevacizumab monotherapy has significant activity in recurrent ovarian cancer (21-23), further research is necessary to confirm this activity in this patient population. Therefore, in this study, bevacizumab monotherapy was administered to patients who refused or were unable to receive cytotoxic agents after offering detailed explanation and receiving informed consent.

In conclusion, our study confirmed that bevacizumab monotherapy was generally tolerable and effective for the treatment of older patients with recurrent ovarian cancer. Bevacizumab monotherapy seems to be a useful treatment option for older patients with recurrent ovarian cancer who refuse or are unable to receive cytotoxic agents due to potential adverse events. To our knowledge, the tolerability and efficacy of bevacizumab monotherapy in older ovarian cancer patients has not been specifically studied. Further research is warranted to validate our observations.

\section{Conflicts of Interest}

Keiichi Fujiwara has received research grants and a speaker honorarium from Chugai-Roche. All other Authors declare that they have no conflicts of interest.

\section{Authors' Contributions}

Study concepts and design: SD, HY; Acquisition of data: SD, AY; Conducting the study: SD, HY; Data analysis and interpretation: SD, AY, HY; Writing, review, and revision of the manuscript: HY; Study supervision: KF. All Authors have read and approved the final manuscript.

\section{Acknowledgements}

The Authors would like to thank all gynecologists at Saitama Medical University International Medical Center for their support and James P. Mahaffey, Ph.D., from Edanz Group (www. edanzediting.com/ac) for editing a draft of this manuscript.

\section{References}

1 Monson K, Litvak DA and Bold RJ: Surgery in the aged population: surgical oncology. Arch Surg 138(10): 1061-1067, 2003. PMID: 14557121. DOI: 10.1001/archsurg.138.10.1061
2 Siegel RL, Miller KD and Jemal A: Cancer statistics, 2019. CA Cancer J Clin 69(1): 7-34, 2019. PMID: 30620402. DOI: 10.3322/caac. 21551

3 Tew WP, Muss HB, Kimmick GG, Von Gruenigen VE and Lichtman SM: Breast and ovarian cancer in the older woman. J Clin Oncol 32(24): 2553-2561, 2014. PMID: 25071129. DOI: 10.1200/JCO.2014.55.3073

4 Eisenhauer EL, Tew WP, Levine DA, Lichtman SM, Brown CL, Aghajanian C, Huh J, Barakat RR and Chi DS: Response and outcomes in elderly patients with stages IIIC-IV ovarian cancer receiving platinum-taxane chemotherapy. Gynecol Oncol 106(2): 381-387, 2007. PMID: 17509673. DOI: 10.1016/j.ygyno. 2007.04.012

5 Fader AN, von Gruenigen V, Gibbons H, Abushahin F, Starks D, Markman M, Belinson J and Rose P: Improved tolerance of primary chemotherapy with reduced-dose carboplatin and paclitaxel in elderly ovarian cancer patients. Gynecol Oncol 109(1): 33-38, 2008. PMID: 18261784. DOI: 10.1016/j.ygyno. 2008.01.001

6 Fairfield KM, Black AW, Lucas FL, Murray K, Ziller E, Korsen $\mathrm{N}$ and Waterston: Completion of adjuvant chemotherapy and use of health services for older women with epithelial ovarian cancer. J Clin Oncol 29(29): 3921-3926, 2011. PMID: 21911719. DOI: $10.1200 /$ JCO.2010.34.1552

7 Yoshida H, Shintani D, Ogasawara A and Fujiwara K: Feasibility and response to nedaplatin monotherapy in older patients with ovarian cancer. Arch Gynecol Obstet 296(4): 819-826, 2017. PMID: 28803267. DOI: 10.1007/s00404-017-4487-5

8 Cannistra SA: Cancer of the ovary. N Engl J Med 351(24): 25192529, 2004. PMID: 15590954. DOI: 10.1056/NEJMra041842

9 Ferrara N, Hillan KJ and Novotny W: Bevacizumab (Avastin), a humanized anti-VEGF monoclonal antibody for cancer therapy. Biochem Biophys Res Commun 333(2): 328-335, 2005. PMID: 15961063. DOI: 10.1016/j.bbrc.2005.05.132

10 Burger RA, Brady MF, Bookman MA, Fleming GF, Monk BJ, Huang H, Mannel RS, Homesley HD, Fowler J, Greer BE, Boente M, Birrer MJ and Liang SX; Gynecologic Oncology Group: Incorporation of bevacizumab in the primary treatment of ovarian cancer. N Engl J Med 365(26): 2473-2483, 2011. PMID: 22204724. DOI: 10.1056/NEJMoa1104390

11 Perren TJ, Swart AM, Pfisterer J, Ledermann JA, PujadeLauraine E, Kristensen G, Carey MS, Beale P, Cervantes A, Kurzeder C, du Bois A, Sehouli J, Kimmig R, Stähle A, Collinson F, Essapen S, Gourley C, Lortholary A, Selle F, Mirza MR, Leminen A, Plante M, Stark D, Qian W, Parmar MK and Oza AM; ICON7 Investigators: A phase 3 trial of bevacizumab in ovarian cancer. N Engl J Med 365(26): 2484-2496, 2011. PMID: 22204725. DOI: 10.1056/NEJMoa1103799

12 Aghajanian C, Blank SV, Goff BA, Judson PL, Teneriello MG, Husain A, Sovak MA, Yi J and Nycum LR: OCEANS: a randomized, double-blind, placebo-controlled phase III trial of chemotherapy with or without bevacizumab in patients with platinum-sensitive recurrent epithelial ovarian, primary peritoneal, or fallopian tube cancer. J Clin Oncol 30(17): 20392045, 2012. PMID: 22529295. DOI: 10.1200/JCO.2012.42.0505

13 Pujade-Lauraine E, Hilpert F, Weber B, Reuss A, Poveda A, Kristensen G, Sorio R, Vergote I, Witteveen P, Bamias A, Pereira D, Wimberger P, Oaknin A, Mirza MR, Follana P, Bollag D and Ray-Coquard I: Bevacizumab combined with chemotherapy for platinum-resistant recurrent ovarian cancer: the AURELIA open- 
label randomized phase III trial. J Clin Oncol 32(13): 13021308, 2014. PMID: 24637997. DOI: 10.1200/JCO.2013.51.4489

14 Yoshida H, Yabuno A and Fujiwara K: Critical appraisal of bevacizumab in the treatment of ovarian cancer. Drug Des Devel Ther 28(9): 2351-2358, 2015. PMID: 25960638. DOI: 10.2147/DDDT.S83275

15 Beinse G, Emile G, Cessot A, Boudou-Rouquette P, Huillard O, Saidu NE, Borghese B, Goldwasser F, Pujade Lauraine E and Alexandre J: A real-life experience of bevacizumab in elderly women with advanced ovarian carcinoma. Int J Gynecol Cancer 26(7): 1196-1200, 2016. PMID: 27643645. DOI: 10.1097/ IGC.0000000000000833

16 Sorio R, Roemer-Becuwe C, Hilpert F, Gibbs E, García Y, Kaern J, Huizing M, Witteveen P, Zagouri F, Coeffic D, Lück HJ, González-Martín A, Kristensen G, Levaché CB, Lee CK, Gebski $\mathrm{V}$ and Pujade-Lauraine E; AURELIA Investigators: Safety and efficacy of single-agent bevacizumab-containing therapy in elderly patients with platinum-resistant recurrent ovarian cancer: Subgroup analysis of the randomised phase III AURELIA trial. Gynecol Oncol 144(1): 65-71, 2017. PMID: 27871723. DOI: 10.1016/j.ygyno.2016.11.006

17 Selle F, Colombo N, Korach J, Mendiola C, Cardona A, Ghazi $\mathrm{Y}$ and Oza AM: Safety and efficacy of extended bevacizumab therapy in elderly ( $\geq 70$ years) versus younger patients treated for newly diagnosed ovarian cancer in the international ROSiA study. Int J Gynecol Cancer 28(4): 729-737, 2018. PMID: 29498983. DOI: $10.1097 /$ IGC.0000000000001221

18 Pecorelli S: Revised FIGO staging for carcinoma of the vulva, cervix, and endometrium. Int J Gynaecol Obstet 105(2): 103104, 2009. PMID: 19367689. DOI: 10.1016/j.ijgo.2009.02.012

19 National Cancer Institute: Common Terminology Criteria for Adverse Events (CTCAE) version 4.0. Available at: http://ctep. cancer.gov/protocolDevelopment/electronic_applications/ctc.htm \#ctc_40(Last accessed on 3rd February 2018)
20 Therasse P, Arbuck SG, Eisenhauer EA, Wanders J, Kaplan RS, Rubinstein L, Verweij J, Van Glabbeke M, van Oosterom AT, Christian MC and Gwyther SG: New guidelines to evaluate the response to treatment in solid tumors. European Organization for Research and Treatment of Cancer, National Cancer Institute of the United States, National Cancer Institute of Canada. J Natl Cancer Inst 92(3): 205-216, 2000. PMID: 10655437. DOI: 10.1093/jnci/92.3.205

21 Burger RA, Sill MW, Monk BJ, Greer BE and Sorosky JI: Phase II trial of bevacizumab in persistent or recurrent epithelial ovarian cancer or primary peritoneal cancer: A Gynecologic Oncology Group Study. J Clin Oncol 25(33): 5165-5171, 2007. PMID: 18024863. DOI: 10.1200/JCO.2007.11.5345

22 Cannistra SA, Matulonis UA, Penson RT, Hambleton J, Dupont J, Mackey H, Douglas J, Burger RA, Armstrong D, Wenham R and McGuire W: Phase II study of bevacizumab in patients with platinum-resistant ovarian cancer or peritoneal serous cancer. $\mathbf{J}$ Clin Oncol 25(33): 5180-5186, 2007. PMID: 18024865. DOI: 10.1200/JCO.2007.12.0782

23 Emile G, Chauvenet L, Tigaud JM, Chidiac J, Pujade Lauraine E and Alexandre J: A clinical experience of single agent bevacizumab in relapsing ovarian cancer. Gynecol Oncol 129(3): 459-462, 2013. PMID: 23474345. DOI: 10.1016/j.ygyno. 2013.02.035
Received January 4, 2020

Revised February 3, 2020

Accepted February 4, 2020 